\title{
Crew Exploration Vehicle Environmental Control and Life Support Development Status
}

\author{
John F. Lewis ${ }^{1}$, Richard A. Barido ${ }^{2}$, and Cynthia D. Cross ${ }^{3}$. \\ NASA Johnson Space Center, Houston, Texas, 77058 \\ Robyn Carrasquillo ${ }^{4}$ \\ NASA Marshal Space Flight Center, Huntsville, Alabama, 35812 \\ and \\ George Edward Rains ${ }^{5}$ \\ Jacobs Engineering, Houston, Texas, 77058
}

\begin{abstract}
The Orion Crew Exploration Vehicle (CEV) is the first crew transport vehicle to be developed by the National Aeronautics and Space Administration (NASA) in the last thirty years. The CEV is currently being developed to transport the crew safely from the Earth to the Moon and back again. This year, the vehicle focused on building the Orion Flight Test 1 (OFT1) vehicle to be launched in 2013. The development of the Orion Environmental Control and Life Support (ECLS) System, focused on the components which are on OFT1 which includes pressure control and active thermal control systems, is progressing through the design stage into manufacturing. Additional development work was done to keep the remaining component progressing towards implementation. This paper covers the Orion ECLS development from April 2010 to April 2011.
\end{abstract}

${ }^{1}$ Orion ECLS System Manager, EC6/Crew and Thermal Systems Divison

${ }^{2}$ Orion ECLS ARS Subsystem Manager, EC6/Crew and Thermal Systems Divison

${ }^{3}$ Orion ECLS ATCS Subsystem Manager, EC6/Crew and Thermal Systems Divison

${ }^{4}$ Orion Crew and Thermal FAM, Systems Development, Integration, and Test, ES62. AIAA Member

${ }^{5}$ Orion ECLS PSC Subsystem Manager, EC6/Crew and Thermal Systems Divison. 


\title{
Crew Exploration Vehicle Environmental Control and Life Support Development Status
}

\author{
John F. Lewis ${ }^{1}$, Richard A. Barido ${ }^{2}$, and Cynthia D. Cross ${ }^{3}$ \\ NASA Johnson Space Center, Houston, Texas, 77058 \\ Robyn Carrasquillo ${ }^{4}$ \\ NASA Marshal Space Flight Center, Huntsville, Alabama, 35812 \\ and \\ George Edward Rains ${ }^{5}$ \\ Jacobs Engineering, Houston, Texas, 77058
}

\begin{abstract}
The Orion Crew Exploration Vehicle (CEV) is the first crew transport vehicle to be developed by the National Aeronautics and Space Administration (NASA) in the last thirty five years. The CEV is currently being developed to transport the crew safely from the Earth to the Moon and back again. This year, the vehicle focused on building the Orion Flight Test 1 (OFT1) vehicle to be launched in 2013. The development of the Orion Environmental Control and Life Support (ECLS) System, focused on the components which are on OFT1 which includes pressure control and active thermal control systems, is progressing through the design stage into manufacturing. Additional development work was done to keep the remaining component progressing towards implementation. This paper covers the Orion ECLS development from April 2010 to April 2011.
\end{abstract}

\section{Introduction}

$\mathrm{D}$ evelopment of the Orion spacecraft has evolved from requirements refinement to specifying and procuring components while being pushed to fit within the design space of mass, power, and volume along with cost and schedule. This paper will encompass changes to the Orion Environmental Control and Life Support (ECLS) System design and requirements since May 2009. This is the 5th in a series of ICES papers on Orion ECLS development status (ref 1, 2, 3, 4).

This was an interesting year with PDR, budget issues, and an Administration change in NASA direction. The project struggled to find the best design to fit within all of these challenges.

Figure 1: Orion Spacecraft

\footnotetext{
${ }^{1}$ Orion ECLS System Manager, Crew and Thermal Division, EC6.

${ }^{2}$ Orion ECLS ARS Subsystem Manager, Crew and Thermal Division, EC6.

${ }^{3}$ Orion ECLS ATCS Subsystem Manager, Crew and Thermal Division, EC6.

${ }^{4}$ Orion Crew and Thermal FAM, Systems Development, Integration, and Test, ES62. AIAA Member

${ }^{5}$ Orion ECLS PSC Subsystem Manager, Crew and Thermal Division, EC6.
} 


\section{A. Program Reorganization}

As part of a new direction from the United States Congress, The Orion vehicle is in the transition from the Crew Exploration Vehicle (CEV) as part of the Constellation Program's Lunar mission to a Multi-Purpose Crew Vehicle. The MPCV will be part of an architecture that allows NASA to explore the Moon, Lagrangian Points, asteroids, and Mars. The CEV Orion Project Office will become the MPCV Orion Program office.

\section{B. Orion Flight Test One (OFT1)}

As part of reducing cost this year to fit inside of the reduced financial allocations, it was decided to pursue an early flight test called Orion Flight Test One. This flight launches an Orion capsule without crew for two orbits and performs a high speed entry close to Lunar return velocities. For this flight test, only a subset of hardware will be used since crew will not be present. Items like the Launch Abort System, crew interfaces, and life support will be deferred. For ECLS, the Crew Module Active Thermal Control and Cabin Pressure Relief will be part of the flight test. The ECLS components for OFT1 will be built to the current Lunar mission specification, but the integrated vehicle will only be certified to the flight test limits. OFT1 launch is scheduled for late in Fiscal Year 2013.

As part of supporting the OFT1 Flight Test, work started to design, develop, manufacture and test the ECLS components needed. Preliminary and Critical Design Reviews are underway and hardware is being scheduled to be ready by mid-2012.

\section{Orion 2 Work}

The Prime Contractor for the Orion Project only had sufficient funding to support the OFT1 flight test. But, the NASA ECLS used some of their available funding to provide research, analysis, and testing to answer some issues for the Orion 2 and out crewed missions. The team focused on suit interface issues, completing analysis that the Prime contractor had to leave undone, and working post landing hardware issues.

\section{System Status}

\section{A. Active Thermal Control}

OFT1 Configuration: The Active Thermal Control Subsystem (ATCS) configuration includes the pump package of four pumps (redundant pumps on each of two loops), accumulators, Service Module isolation valves, ground support heat exchanger, eleven cold plates, two ammonia tanks, and two ammonia boilers. The ATCS uses a 50\% propylene glycol in water coolant for a thermal transport to provide cooling for vehicle avionics. Cooling is provided from pre-launch using the ground support heat exchanger, thru launch, orbit, re-entry, and landing using the ammonia boilers. Radiators are being built, but do not include the flow tube network since they are not needed for this flight test. Being a consumable based cooling system, after launch there is a fixed capacity for cooling.

Ammonia boiler Tank and Propulsion Helium: It was decided to change the ammonia tank bellows from a metallic to an elastomeric one. This was to maximize the available ammonia for a given volume of tank. Also, a change was made to pressurize the ammonia tanks using the helium pressure system from the Crew Module propulsion system. This avoided having the additional weight and volume of independent helium systems.

Use of Shuttle GSE Heat Exchanger: It was decided to use a Shuttle ground support heat exchanger unit on the OFT1 vehicle to provide ground cooling for the flight test. Testing was performed to show that the Shuttle unit would provide adequate performance with the Orion thermal working fluids.

Liquid Cooling Garment (LCG) Loop Developments: NASA has testing underway to first understand the compatibility between the materials and the water coolant on the liquid cooling garment loop. This will be a long term test to understand the materials performance of the loop. NASA is also investigating the use of a venting gas trap for the liquid cooling garment. During the disconnects and reconnects of the suit to the vehicle systems, gas is entrained into the system and has to be removed to assure pump operation. Baseline design uses a non-venting gas trap that can only separate a fixed amount of gas. If a venting gas trap is possible, it can solve volume problems in the ECLS bay of Orion while reducing operational impacts of limiting or tracking suit connects. 


\section{B. Air Revitalization}

OFT1 Configuration: Since there are no crew for the OFT1 flight test, no air revitalization or suit support in the OFT1 vehicle

Integrated Suit Loop Testing: NASA is building up for an ambient pressure integrated suit loop test using the same test bed planned for the qualification testing of the Orion ECLS suit loop. This provides a progression to the final test and an opportunity to perform development testing to reduce design risks. The loop will use development hardware for the suit loop fan, swing bed, and suit loop regulator. The testing will used a Shuttle launch and entry Advanced Crew Escape Suit (ACES) modified to work with the Orion closed suit loop. The testing will be performed at ambient pressure so that elevated oxygen will not be required allowing testing with existing development hardware.

\section{Pressure Control}

OFT1 Configuration: The Pressure Control Subsystem (PCS) configuration includes a positive pressure relief valve (PPRV) and a negative pressure relief valve (NPRV). The hardware to provide oxygen and nitrogen to the cabin have been deferred from OFT1.

Use of Shuttle Positive Pressure Relief Valve (PPRV): With the OFT1 vehicle not using the fixed fire suppression in the avionics bays, this allowed the use of the Shuttle heritage PPRV. Testing was performed to demonstrate that the PPRV would not excessively leak in the Orion's launch vibration environment.

Negative Pressure Relief Valve(NPRV) Issues: Issues were worked with the NPRV's performance during the reentry profile. The NPRV is only needed if the cabin comes in at a reduced pressure from external ambient to protect the capsule from crushing under the pressure. Work was done to verify that the flow paths for the NPRV were sufficient to perform that relief and that the NPRV would reseat at an appropriate pressure before isolation at landing.

\section{Emergency Response}

OFT1 Configuration: Since there are no crew for the OFT1 flight test, no emergency response in the OFT1 vehicle.

Hydrazine Detector Development: Work was done to determine the best options for a post landing hydrazine sensor from the available commercial units on the market.

\section{E. Potable Water \& Waste Management}

OFT1 Configuration: Since there are no crew or sublimators for the OFT1 flight test, no potable water or waste management in the OFT1 vehicle.

\section{Conclusion}

The Orion ECLS system continues to adjust and proceed to developing a crew launch vehicle as the directions of the project changes. 


\section{References}

${ }^{1}$ Lewis, J., “The Crew Exploration Vehicle Environmental Control and Life Support Development Status - 2006” SAE Technical Paper Series 2006-01-2011, 36th International Conference on Environmental Systems, Newport, VA July 2006.

${ }^{2}$ Lewis, J., Barido, R., Carrasquillo, R., Cross, C., Tuan, G.,"The Crew Exploration Vehicle Environmental Control and Life Support Development Status - 2007” SAE Technical Paper Series 2007-01-3044, 37th International Conference on Environmental Systems, Chicago, IL July 2007.

${ }^{3}$ Lewis, J., Barido, R., Carrasquillo, R., Cross, C., Tuan, G.,"The Crew Exploration Vehicle Environmental Control and Life Support Development Status - 2008” SAE Technical Paper Series 2008-01-2079, 38th International Conference on Environmental Systems, San Francisco, CA July 2008.

${ }^{4}$ Lewis, J., Barido, R., Carrasquillo, R., Cross, C., Tuan, G., “The Crew Exploration Vehicle Environmental Control and Life Support Development Status - 2009” SAE Technical Paper Series 2009-01-2457, 39th International Conference on Environmental Systems, Savannah, GA July 2009.

${ }^{5}$ Lewis, J., Barido, R., Carrasquillo, R., Cross, C., Tuan, G.,"The Crew Exploration Vehicle Environmental Control and Life Support Development Status - 2010” AIAA Technical Paper Series 763172R1, 40th International Conference on Environmental Systems, Barcelona Spain July 2010. 